\title{
Dietary Supplementation of a Mixture of Saponin-Rich Plants to Reduce Ammonia-Nitrogen Excretion in Juvenile Nile Tilapia (Oreochromis niloticus)
}

\author{
Paul Engler ${ }^{1 *}$, Pierre Caillis ${ }^{1}$, Samuel Voller ${ }^{2}$, Laura Labrie $^{2}$ \\ ${ }^{1}$ Nor-Feed SAS, Beaucouzé, France \\ ${ }^{2}$ Ictyopharma SAS, Deuneille-les-Mînes, France \\ *paul.engler@norfeed.net
}

\begin{abstract}
Keywords: Nitrogen excretion, Feed additive, Yucca schidigera, Oreochromis niloticus,
\end{abstract} Aquaculture, Water quality, Saponin, Norponin, Ammonia, RAS, Tilapia

\begin{abstract}
The intensification in aquaculture production leads to increasing attention on the management of ammonia from its waste. Natural solutions such as Yucca schidigera extracts have shown beneficial effects. Their origin (harvested from the wild), however, call for alternative and equally efficient solutions in order to increase the sustainability of their production. In this work, juvenile Nile tilapias (Oreochromis niloticus) were supplemented with different doses of a commercial mixture of saponin-rich plants (Norponin ${ }^{\circledR}$ OPTI, CTL: 0ppm, D1: 100ppm, D2: 500ppm and D3: 2500ppm). The impact on water quality was monitored, with a particular attention to total ammonia excretion (TAN). TAN was significantly reduced in treatments D1 and D2 compared to the control and D3 treatments $(\mathrm{p}<0.05)$. Overall, the present study demonstrates that a supplementation with low doses of the feed additive (100 or 500ppm) induced beneficial effects on TAN management.
\end{abstract}

\section{Introduction}

Aquaculture production has seen a sharp increase worldwide, through the increase of production capacity and the domestication of new species. One of the main drawbacks of aquaculture is its environmental impact, particularly linked to ammonia excretion by aquatic species. Ammonia is a waste product excreted by aquatic animals as the result of the protein metabolism [1]. Ammonia can also be formed as a result of the mineralization of organic nitrogen from faeces, uneaten feed and other organic matter.

To reduce such impacts, natural solutions have emerged over the last decades, among which is Yucca schidigera. The plant is native to the south-west desert of North-America, ranging from the Nevada region in the USA to the Baja California region in Mexico. It is mainly exploited from the wild for its trunk, due to its richness in saponins, a plant secondary metabolite, used for their ammonia management capacity [2].

This means that the destructive harvest, combined with a long life span due to slow growth, and an increasing demand in animal nutrition, could lead to endangering the natural resource [3].

In order to find alternative solutions to $Y$. schidigera, some research has been conducted on the screening of saponin-containing plants cultivated worldwide, which showed equal capacity to manage ammonia [4], and could allow for a reduced environmental impact of this solution.

The aim of this study was to evaluate the effect of a dietary supplementation of a mixture of saponin-rich plants on the ammonia-nitrogen excretion of a major aquaculture species, Nile Tilapia (Oreochromis niloticus), and to compare different doses in order to assess the most suitable level of supplementation. 


\section{Material and Methods}

\section{Fish and experimental protocol}

The feeding trial consisted of 4 groups, three of which contained the feed additive at various doses, and a control group without any additional product (CTL). The doses of additive tested were D1: 100ppm, D2: 500ppm, D3: 2500ppm. Each treatment group consisted of 120 juvenile Nile Tilapia (O. niloticus) (TilAqua, The Netherlands). Only healthy animals were used. A health check was performed before release from quarantine to ensure the good health of the animals. The animals were acclimatised to their tanks 4 days before the start of the experiment. During this phase, all animals were fed the same non-supplemented diet. The average weight of juvenile fish at the beginning of the experiment was $24.7 \pm 0,7 \mathrm{~g}$.

Fish feeds were prepared as follows: the same feed (Start Premium, COPPENS, 1.5mm, The Netherlands) was divided into 4 batches. For each group, the feed was pre-coated with cod liver oil and subsequently the active product was added to the diets. Feed was then post-coated with the same quantity of cod liver oil. The control diet (CTL, un-supplemented) followed the same protocol, but without addition of the saponin-rich feed additive.

Fish were fed with the feeds for a period of 3 weeks using 4 feedings a day at pre-determined time points $(9 \mathrm{H} 30,11 \mathrm{H} 00,13 \mathrm{H} 00$ and $16 \mathrm{H} 00,25 \%$ of the total amount of feed at each feeding time point). Feeding rates are described in the Table 1.

Table 1. Feeding rates of the fish used during the study

\begin{tabular}{|c|c|}
\hline Mean fish weight $(\mathrm{g})$ & $\begin{array}{c}\text { Feeding rate } \\
\text { (\% biomass/day) }\end{array}$ \\
\hline $15-30$ & 4.5 \\
\hline $30-40$ & 4.0 \\
\hline $40-50$ & 3.7 \\
\hline $50-70$ & 3.3 \\
\hline
\end{tabular}

Fish were housed in 4 separate recirculation systems (RAS), each consisting of $1 \times 450 \mathrm{~L}$ rectangular tank. Each tank was equipped with a buffer tank, a mechanical filter (faecal trap) and bio-filtration as well as UV. Photoperiod was controlled: $12 \mathrm{~h} / 12 \mathrm{~h}$. Water temperature was controlled through room temperature around $29^{\circ} \mathrm{C}$. Turnover time of water recirculation of each fiberglass tank was $750 \mathrm{~L} / \operatorname{tank} / \mathrm{h}$.

Fish were observed daily for abnormal behaviour (abnormal swimming, listlessness on the bottom on the tank, blackening or external clinical signs), feed intake and mortality/morbidity.

\section{Sampling and Chemical Analysis}

\section{Water quality measurements}

Active biofilters were added to the systems before the start of the experiment. Biofilters were provided by a biofilter starter room where active biofilters are maintained using chemical NH4 for maintenance.

Water dissolved Oxygen (DO), $\mathrm{pH}$ and temperature were measured on a daily basis. $\mathrm{NO} 2$ was measured at least 2 times a week. The water analysis was conducted following standard operating procedures.

\section{Determination of total ammonia-nitrogen excretion (TAN)}

$\mathrm{NH} 4$ analysis was performed 3 times a day for 5 consecutive days during week days with a HI700 mini photometer checker HC NH4 low range (Hannah Instruments) using reagents HI700 A and $\mathrm{B}$ for analysis. Measurements were performed according to manufacturer instructions and were 
performed 3 times daily, according to the feeding schedule (9am before feeding, noon and evening (16h00) one hour after the last feeding).

\section{Statistical analysis}

Mean values of daily $\mathrm{DO}, \mathrm{pH}$, temperature and $\mathrm{NO}_{2}$ throughout the experimental time were compared between groups by a one-way ANOVA statistical analysis using R software (v. 3.4.1 [5]). A two-way ANOVA statistical analysis was used to compare the effect of the diet and the week on the average NH4 daily values. The differences between groups were evaluated with a Tukey's range test. Significant differences among treatment means were determined at $p<0.05$.

\section{Results}

All fish groups grew well and no abnormal behaviour was observed during the length of the trial. Percentage survival was $100 \%$ for all treatments.

\section{Water quality parameters}

DO measurements, showed a significant reduction in the group supplemented with the highest proportion of saponin-rich plants (D3 group, $5.20 \mathrm{mg} / \mathrm{L}$ ) as compared with the D2 group $\left(5.78 \mathrm{mg} / \mathrm{L}, \mathrm{p}<0,05\right.$, ANOVA). Supplementation of the diet with lower doses of Norponin ${ }^{\circledR}$ OPTI however did not impair this parameter, since the highest mean DO value was observed in the D2 group (500ppm).

Water analyses did not show significant differences between groups for the $\mathrm{pH}$ or temperature (Table 2). Additionally, the presence of Norponin ${ }^{\circledR}$ OPTI in the diet did not seem to significantly impact the $\mathrm{NO}_{2}$ concentration in the water, despite a numerically lower concentration in the D2 group (500ppm) as compared to the control group (1.90 vs. $2.40 \mathrm{mg} / \mathrm{L}$ respectively).

Table 2. Mean water quality parameters measurements ( $\mathrm{DO}, \mathrm{pH}$, temperature and $\mathrm{NO}_{2}$ ) in tanks of Nile Tilapia (O. niloticus) fed diet with different doses of a commercial mixture of saponin-rich plants

\begin{tabular}{|c|c|c|c|c|}
\hline Group & CTL - Control & D1 - 100ppm & D2 - 500ppm & D3- 2500ppm \\
\hline Mean DO $(\mathrm{mg} / \mathrm{L})$ & $5.39^{\mathrm{ab}} \pm 0.38$ & $5.55^{\mathrm{ab}} \pm 0.35$ & $5.78^{\mathrm{b}} \pm 0.45$ & $5.20^{\mathrm{a}} \pm 0.37$ \\
\hline Mean pH & $7.39 \pm 0.17$ & $7.42 \pm 0.11$ & $7.49 \pm 0.17$ & $7.48 \pm 0.18$ \\
\hline Mean T $\left({ }^{\circ} \mathrm{C}\right)$ & $29.5 \pm 0.4$ & $29.2 \pm 0.3$ & $29.2 \pm 0.4$ & $29.2 \pm 0.5$ \\
\hline Mean NO2 $(\mathrm{mg} / \mathrm{L})$ & $2.40 \pm 0.69$ & $2.75 \pm 2.36$ & $1.90 \pm 0.82$ & $2.00 \pm 1.15$ \\
\hline
\end{tabular}

${ }^{\mathrm{a}, \mathrm{b}}$ Means in a row with different superscripts differ significantly $(\mathrm{p}<0.05)$

\section{Total ammonia-nitrogen excretion}

Total ammonia-nitrogen excretion measured in the first two weeks did not reveal significant differences between groups (Fig. 1). Data collected during the third week of the trial however showed a significant increase of TAN in the water from the CTL and D3 groups as compared to that of week two ( 0.96 vs. 0.70 for CTL and 0.86 vs. 0.59 for D3 respectively, $p<0,05$, ANOVA), whilst measurements of this parameter in the D1 and D2 groups did not show any significant increase. Moreover, the average TAN excretion of D1 and D2 was significantly lower than that of the control group $(0.68,0.67$ and $0.96 \mathrm{mg} / \mathrm{L}$ respectively, $\mathrm{p}<0,05$, ANOVA). 


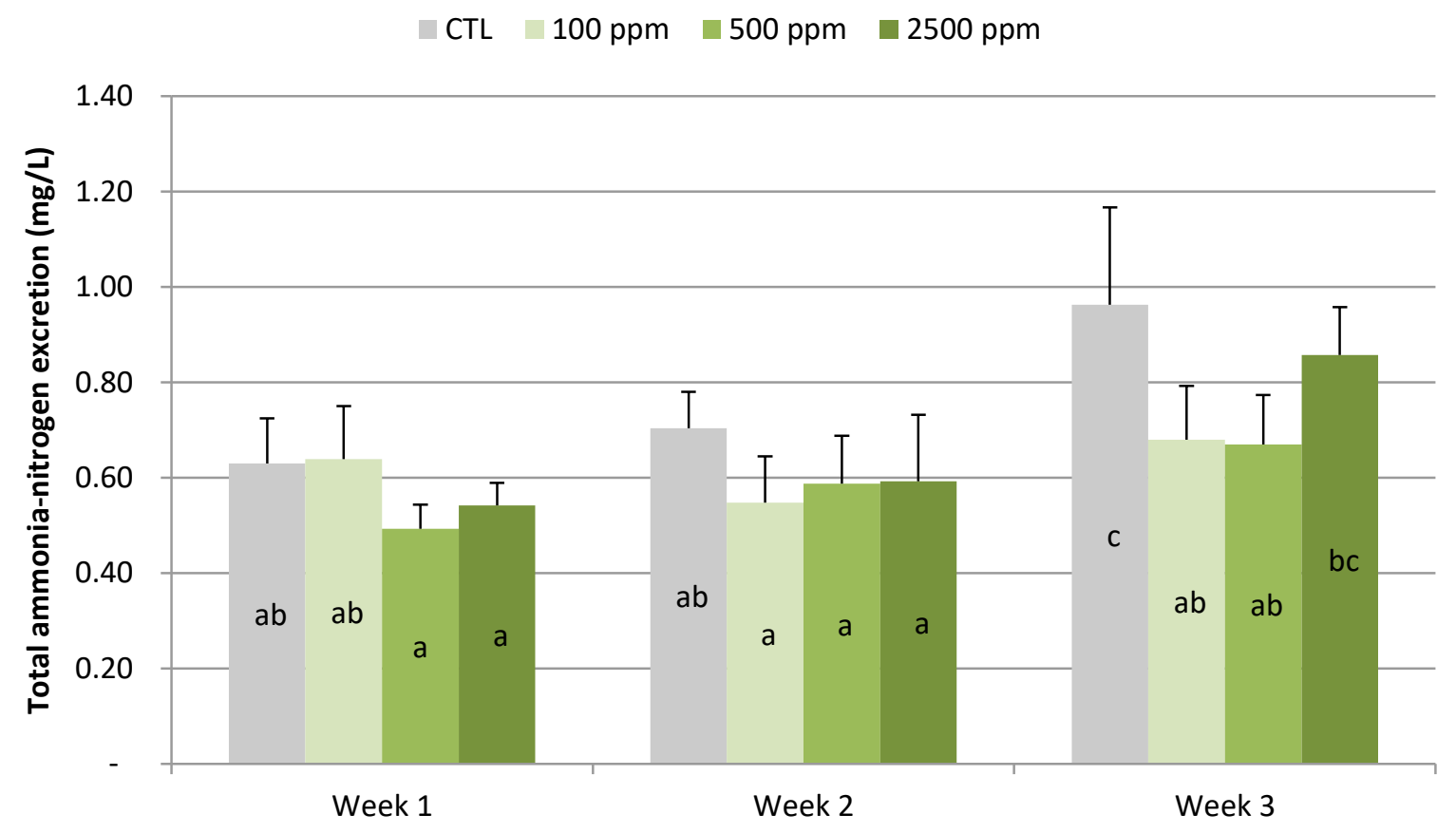

${ }^{\mathrm{a}, \mathrm{b}, \mathrm{c}}$ Means with a common letter superscript are not significantly different $(\mathrm{p}<0.05)$.

Figure 1. Mean (S.D.) total ammonia-nitrogen levels in tanks of Nile Tilapia (O. niloticus) fed diet with different doses of a commercial mixture of saponin-rich plants

\section{Discussion}

While there is no other published data of the action of Norponin ${ }^{\circledR}$ OPTI on aquaculture species, previous studies have evidenced a beneficial role of relatively small amounts of saponinrich plants in fish diets.

The dietary use of small amounts of saponin-containing plants such as $Y$. schidigera $(750 \mathrm{ppm}$ [6]) or Quillaja saponaria (300ppm [7]) was shown to significantly improve growth performances in Nile Tilapia (O. niloticus).

Contrastingly, Kelly and Kohler [8], and Njagi et al. [9], reported no effect of Y. schidigera extract $(1000 \mathrm{ppm})$ or $Y$. shidigera meal $(1000 \mathrm{ppm})$ on the growth performances of juvenile hybrid tilapia (O. mossambicus $x$ O. niloticus) and juvenile Nile Tilapia (O. niloticus) respectively.

Other studies showed divergent effects of a $Y$. shidigera supplementation in different fish species. Amoah et al. [10] indeed reported a beneficial impact of a 500ppm Y. schidigera meal on growth performances in juvenile Amur catfish (Silurus asotus), whilst Tidwell et al. showed that the use of a supplementation with 1100ppm Y. schidigera extract in juvenile channel catfish (Ictalurus punctatus) in recirculated aquaculture system led to decrease performances and feed utilization [11].

Moreover, similar results have also been reported in other fish species. Gu et al. [12] thus reported a beneficial role of soybean-saponins in Atlantic salmon (Salmo salar) fry resulting in increased growth, associated with an increased liver function. However, they did not improve juveniles seabream (Sparus aurata [13], [14]), European seabass (Dicentrarchus labrax [15]), juvenile turbot (Scophthalmus maximus [16]) or juvenile Japanese flounder (Paralichthys olivaceus [17]) growth performances.

Francis et al. [18], and Serrano [19] also evidenced a beneficial impact of a supplementation with $Q$. saponaria on the growth of common carp (Cyprinus carpio).

Güroy et al. [20] showed a beneficial impact of a supplementation of juvenile striped catfish (Pangasianodon hypophthalmus) with a mixture of $Y$. schidigera and $Q$. saponaria, on the fish growth. 
Overall, in results obtained in the litterature on the use of saponin-rich plants in aquaculture, an improvement seems to be observed for supplementation doses lower than 1000ppm.

Chen et al. [17] hypothetised that increasing growth in fish fed the diets with lower saponin rates could be due to intensification in the nutrient absorption from the intestine, induced by a slight permeabilization of the intestinal walls with saponins. This would explain why low doses $(<1000 \mathrm{ppm})$ of saponin-rich plant extracts can exert a beneficial impact on fish growth, whilst too high doses participate in the development of enteritis.

Additionally, a supplementation of the saponin-rich product at doses as high as $2500 \mathrm{ppm}$ did not appear to impact percentage survival over the studied period. The high dietary level of saponins in this diet (D3) was thus regarded as safe for the Nile tilapia.

While many studies have shown beneficial impact of saponins-rich plants on growth performances, little research has evidenced their consequences on the reduction of TAN, either through their direct addition to rearing water, or through their inclusion in the fish feed. SantacruzReyes and Chien demonstrated a decrease in the TAN level with the addition of $Y$. shidigera extract in the aquaria of Nile tilapia (O. niloticus [21]) and juvenile Kuruma shrimp (Marsupenaeus japonicas [1]). Vargasmachuca et al. demonstrated similar effects with $Y$. schidigera extract added to the water of Pacific Red Snapper (Lutjanus peru) during acclimatization [22]. In some cases, however, such use resulted in the death of all animals after a few hours [1].

The addition of saponins in the diet of aquatic animals to reduce TAN excretion has not been the subject of much research. Yang et al. reported that a supplementation of $Y$. schidigera extract in Pacific white shrimp (Litopenaeus vannamei) significantly improved growth performances and significantly reduced the TAN in the supplemented groups [23].

Tidwell et al., showed that the use of a 1100ppm Y. schidigera extract supplementation in juvenile channel catfish (I. punctatus) in recirculated aquaculture system led to decrease performances and feed utilization, but with no significant impact on the water quality [11].

Finally, Güroy et al., reported a beneficial impact of a supplementation of juvenile striped catfish (P. hypophthalmus) with a mixture of $Y$. schidigera and $Q$. saponaria, on the fish TAN reduction, associated with an improvement in fish growth [20].

In this study, the addition of the saponin-rich feed additive in the diet of juvenile tilapia resulted in a better management of the TAN excretion for the D1 (100ppm) and D2 (500ppm) diets, reducing the levels of TAN in the RAS systems compared to the control treatment, whereas, a higher dose of the product (2500ppm) did not provide the same beneficial effect.

The increase in intestinal permeabilization by saponins, described by Chen et al. [17] and Knusden et al. [24] leading to a better uptake of the feed nutrient could potentially explain the sgnificantly better control of the TAN excretion by the D1 (100ppm) and D2 (500ppm) groups.

Furthermore, saponins from $Q$. saponiaria have been shown to improve the oxygen uptake per mass of body gain in common carp, meaning that less oxygen is consumed in the supplemented group to achieve the same growth [25]. The authors indicate that the lower amount of oxygen consumed per unit body mass gained associated with a higher energy retention means that saponins improve metabolic efficiency in common carp. Comparatively, TAN excretion was significantly controlled in the D1 and D2 groups supplemented respectively with 100ppm and 500ppm of the saponin-rich feed additive, where the DO had the highest values. The supplementation with a low dose of the feed additive could therefore induce a better uptake of nutrients and improve the metabolic efficiency in Nile tilapia, resulting in a lower TAN excretion and improved growth.

The inclusion of $100 \mathrm{ppm}$ and $500 \mathrm{ppm}$ of Norponin ${ }^{\circledR}$ OPTI in the diet of juvenile Nile tilapia therefore appears to have the most beneficial effect on water quality parameters.

\section{Conclusion}

In conclusion, dietary supplementation with $100 \mathrm{ppm}$ or $500 \mathrm{ppm}$ of Norponin ${ }^{\circledR}$ OPTI saponin-rich feed additive led to a reduced TAN excretion in juvenile Nile tilapia raised in recirculated aquaculture systems. 
Further research is needed to better understand these effects and their impact on growth performances.

The use of such a feed additive could therefore be beneficial for a better control of TAN excretion in aquaculture, reducing environmental impacts.

\section{Conflict of Interest}

The authors declare no conflict of interest.

\section{Acknowledgments}

The authors would like to thank Pierre Chicoteau for the constructive discussions over the manuscript.

\section{References}

[1] R.A. Santacruz-Reyes, Y.-H. Chien, Yucca schidigera extract - A bioresource for the reduction of ammonia from mariculture, Bioresour. Technol. 101(14) (2010) 5652-5657.

[2] R.A. Santacruz-Reyes, Y.-H. Chien, Ammonia reduction in seawater by Yucca schidigera extract: efficacy analysis and empirical modelling, Aquac. Res. 41(8) (2010) 1221-1228.

[3] M. Arce-Montoya et al., No correlation between the growth of in vitro cultured Yucca valida clones and the growth of their mother plants in the field, Plant Cell Tissue Organ Cult. 88(1) (2007) 35 .

[4] A. Budan et al., Effect of several saponin containing plant extracts on rumen fermentation in vitro, Tetrahymena pyriformis and sheep erythrocytes, J. Food Agric. Environ. 11(2) (2013) 576-582.

[5] R. Core Team, R: A language and environment for statistical computing, R Foundation for Statistical Computing, Vienna, Austria, 2017.

[6] M.M. Gaber, The effects of plant-protein-based diets supplemented with yucca on growth, digestibility, and chemical composition of Nile tilapia (Oreochromis niloticus, L) fingerlings, J. World Aquac. Soc. 37(1) (2006) 74-81.

[7] G. Francis, H.P.S. Makkar, K. Becker, Effects of Quillaja saponins on growth, metabolism, egg production and muscle cholesterol in individually reared Nile tilapia (Oreochromis niloticus), Comp. Biochem. Physiol. Part C. Toxicol. Pharmacol. 129(2) (2001) 105-114.

[8] A.M. Kelly, C.C. Kohler, Effects of Yucca shidigera extract on growth, nitrogen retention, ammonia excretion, and toxicity in channel catfish Ictalurus punctatus and hybrid tilapia Oreochromis mossambicus $\times$ O. niloticus, J. World Aquac. Soc. 34(2) (2003) 156-161.

[9] G.W. Njagi et al., Effects of dietary Yucca meal on growth, haematology, non-specific immune responses and disease resistance of juvenile Nile tilapia, Oreochromis niloticus (Linnaeus, 1758), Aquac. Res. 48(8) (2017) 4399-4408.

[10] Y.T. Amoah et al., Evaluation of different dietary additives based on growth performance, innate immunity and disease resistance in juvenile Amur catfish, Silurus asotus, Int. Aquat. Res. 9(4) (2017) 351-360.

[11] J.H. Tidwell et al., Effects of Yucca shidigera extract on water quality and fish growth in recirculating-water aquaculture systems, Progress. Fish-Cult. 54(3) (1992) 196-201.

[12] M. Gu et al., Effects of diet supplementation of soya-saponins, isoflavones and phytosterols on Atlantic salmon (Salmo salar, L) fry fed from start-feeding, Aquac. Nutr. 21(5) (2015) 604-613. 
[13] A. Couto et al., Effects of dietary soy saponins and phytosterols on gilthead sea bream (Sparus aurata) during the on-growing period, Anim. Feed Sci. Technol. 198 (2014) 203214.

[14] A. Couto et al., Effects of dietary phytosterols and soy saponins on growth, feed utilization efficiency and intestinal integrity of gilthead sea bream (Sparus aurata) juveniles, Aquaculture. 432 (2014) 295-303.

[15] A. Couto et al., Saponins and phytosterols in diets for European sea bass (Dicentrarchus labrax) juveniles: effects on growth, intestinal morphology and physiology, Aquac. Nutr. 21(2) (2015) 180-193.

[16] B. Yun et al., Effects of soya saponins on feed intake, growth performance, and cholesterol metabolism in juvenile turbot (Scophthalmus maximus L), The Israeli Journal of Aquaculture - Bamidgeh. (2015).

[17] W. Chen et al., Effects of dietary soybean saponins on feed intake, growth performance, digestibility and intestinal structure in juvenile Japanese flounder (Paralichthys olivaceus), Aquaculture. 318(1) (2011) 95-100.

[18] G. Francis, H.P.S. Makkar, K. Becker, Effects of cyclic and regular feeding of a Quillaja saponin supplemented diet on growth and metabolism of common carp (Cyprinus carpio L.), Fish Physiol. Biochem. 24(4) (2001) 343.

[19] A.E. Serrano, Effects of Quillaja saponins on growth, feed efficiency, digestive enzyme activities and metabolism of common carp (Cyprinus carpio L), Aquac. Nutr. 19(4) (2013) $468-474$.

[20] B. Güroy et al., Effects of dietary Nutrafito Plus on growth, haemotological parameters and total ammonia-nitrogen excretion of juvenile striped catfish Pangasianodon hypophthalmus, Aquac. Res. 47(6) (2016) 1770-1777.

[21] R.A. Santacruz-Reyes, Y.-H. Chien, Efficacy of Yucca schidigera extract for ammonia reduction in freshwater: Effectiveness analysis and empirical modeling approach, Aquaculture. 297(1) (2009) 106-111.

[22] S. Vargasmachuca et al., The effect of Yucca schidigera liquid extract on water quality and survival of Pacific Red Snapper Lutjanus Peru during acclimatization, Arch. Med. Vet. 47 (2015) 107-109.

[23] Q. Yang et al., Effects of different levels of Yucca schidigera extract on the growth and nonspecific immunity of Pacific white shrimp (Litopenaeus vannamei) and on culture water quality, Aquaculture. 439(Supplement C) (2015) 39-44.

[24] D. Knudsen et al., Dietary soya saponins increase gut permeability and play a key role in the onset of soyabean-induced enteritis in Atlantic salmon (Salmo salar L.), Br. J. Nutr. 100(1) (2008) 120-129.

[25] G. Francis, H.P.S. Makkar, K. Becker, Dietary supplementation with a Quillaja saponin mixture improves growth performance and metabolic efficiency in common carp (Cyprinus carpio L.), Aquaculture. 203(3) (2002) 311-320. 